\title{
Development of Low Cost Coconut Water Vinegar Making Process and Evaluation of "Generator Process" to Accelerate the Acetification
}

\author{
K.D.P.P. Gunathilake ${ }^{1 *}$, J.A.K.M. Fernando ${ }^{1} \&$ D.S. Jayawickrama ${ }^{2}$
}

\begin{abstract}
Attempts were made to develop an appropriate low cost vinegar making technique and evaluate the physico-chemical, microbial and sensory qualities of the product. Coconut water was adjusted to four different levels of sugar levels $(12 \%, 15 \%, 17 \%$, and 20\%) and pasteurized sweetened coconut water was allowed for alcoholic fermentation for one week by addition of baker's yeast and then for acetic fermentation by addition of raw vinegar at $10 \%$. Changes in alcohol \%, titratable acidity, $\mathrm{pH}$ and yeast and mold count were determined periodically. Best treatment was selected for evaluation of the vinegar generator. Vinegar generator consists of a feeding device, an acetifier and a receiving trough. The acetifier was filled up with maize cobs soaked with mother vinegar. The maximum alcohol content was observed in $17^{0}$ TSS coconut water sample on $5^{\text {th }}$ day $(9 \%)$ of alcohol fermentation and the same sample achieved the highest acetic acid level during acetic fermentation period. Results indicated that vinegar generator accelerates the conversion of alcohol to acetic acid within 5 cycles or runs. It takes about 32 hours to obtain the $4 \%$ acetic level. Sensory evaluation was done to determine the acceptability of product using 30 untrained panelists. Sensory evaluation revealed that coconut toddy vinegar and coconut water vinegar were highly acceptable for aroma, taste, color, appearance and overall acceptability. Mature coconut water can be used to produce vinegar with the aid of vinegar generator for accelerating the production process.
\end{abstract}

Keywords: coconut water, vinegar, generator process, vinegar generator

1. Coconut Processing Research Division, Coconut Research Institute, Lunuwila, 61150, Sri Lanka.

Email*kdppgunathilake@yahoo.com Fax: +94312257391

$1 *$ Current address: 106/3A, Palenwatta, Pannipitiya, Sri Lanka.

*Email: kdppgunathilake@yahoo.com

2. Department of Food Science \& Technology, Faculty of Agriculture, University of Ruhuna, Mapalana, Kamburupitiya, Sri Lanka. 


\section{Introduction}

Coconut occupies approximately 394836 ha of cultivable land area in Sri Lanka (Anon, 2004a). Sri Lanka, considered as the fourth largest coconut producer in the world and average annual production is around 3000 million nuts and $70 \%$ of country's production is for domestic consumption and rest is for the industries. Since Sri Lanka produce of desiccated coconut 50000 MT per year, over 60 million liters coconut water are discarded through factories annually. Coconut water contains $4.79 \%$ total solid, $2.56 \%$ of sugars, $0.74 \%$ oil and $0.55 \%$ protein, other than that trace amounts of vitamins and minerals, also hormones present in coconut water (Anon, 2004b). Though coconut water is available in plenty in most coconut growing areas in the country, there is no any industrial application for the product has been suggested so far. It is now a waste product of the copra and desiccated coconut industries. Manufacturing a beverage from coconut water is not timely, because there are so many popular branded beverages in the market. Production of vinegar by using coconut water is beneficial to utilize wasting coconut water through the desiccated coconut factories, to introduce an income generating industry, to make available vinegar at reasonable price and to prevent the consumer from harmful effects of artificial vinegar. Also it is environmental sound application for the wasting coconut water.

In general terms, vinegar may be defined as a condiment made from watery solutions of sugar or starchy materials containing yeast and bacteria by alcoholic and subsequent acetous fermentation. The term vinegar has always been used to describe the fermented product. This is generally used with a prefix indicative of the raw material used for its production e.g. coconut toddy vinegar, fruit vinegar, malt vinegar (SLSI, 1999).

At present the major part of the vinegar consumed in Sri Lanka is of synthetic origin made from commercial acetic acid and essences, because of the slow methods used in the traditional production of coconut vinegar and unavailability of toddy, this commodity has become increasingly scarce and expensive. A vinegar generator developed for coconut toddy vinegar is a continuous and provides a steady and efficient production of vinegar with low working losses Fernandez, W.L., (1988). The process combines speed of action with high fermentation efficiencies resulting higher acid strengths of the finished vinegar. It may be operated at low cost, and is relatively simple and easy to control. (Coconut Research Institute (1971). This process can be applied for coconut water vinegar making process. This study was done in order to identify suitable method to prepare coconut water vinegar with low cost and to identify its physico-chemical and sensory properties.

\section{Materials and Methods}

Coconut water was collected from Mawathagama DC mill, Dankotuwa, Sri Lanka. Coconut water was adjusted to four different sugar levels $(12 \%, 15 \%, 17 \%$, and $20 \%)$ and pasteurized sweetened coconut water allowed for alcoholic fermentation for one week by addition of baker's yeast. Changes in alcohol\%, titratable acidity, $\mathrm{pH}$ and yeast and mold count were determined daily. The alcoholic product obtained from the yeast fermentation of sugared coconut water was further fermented to vinegar by adding $10 \%$ mother vinegar. Acidification period was 40 days. Changes in acidity and alcohol\% were observed weekly. Best treatment was selected for evaluation of the vinegar generator. Alcohol level was measured according to the method used by Samarajeewa, U. et.al (1974) and titratable acidity was measured according to the method described in AOAC (1995)

The improved vinegar generator was comprised of a feed vat, an acetifier and a receiving trough. Feed vat - a 501 capacity plastic bucket was used as the feed vat. A plastic tap was fitted to regulate the feeding rate. The feed vat was connected to the acetifier, by rubber tubing. The fermented and pasteurized, alcoholic coconut water was stored in the feed vat. The acetifier is a plastic bucket of 1001 , with three superimposed compartments, and separated by perforated wooden shelves. The 
Figure 1. Schematic View of Vinegar Generator

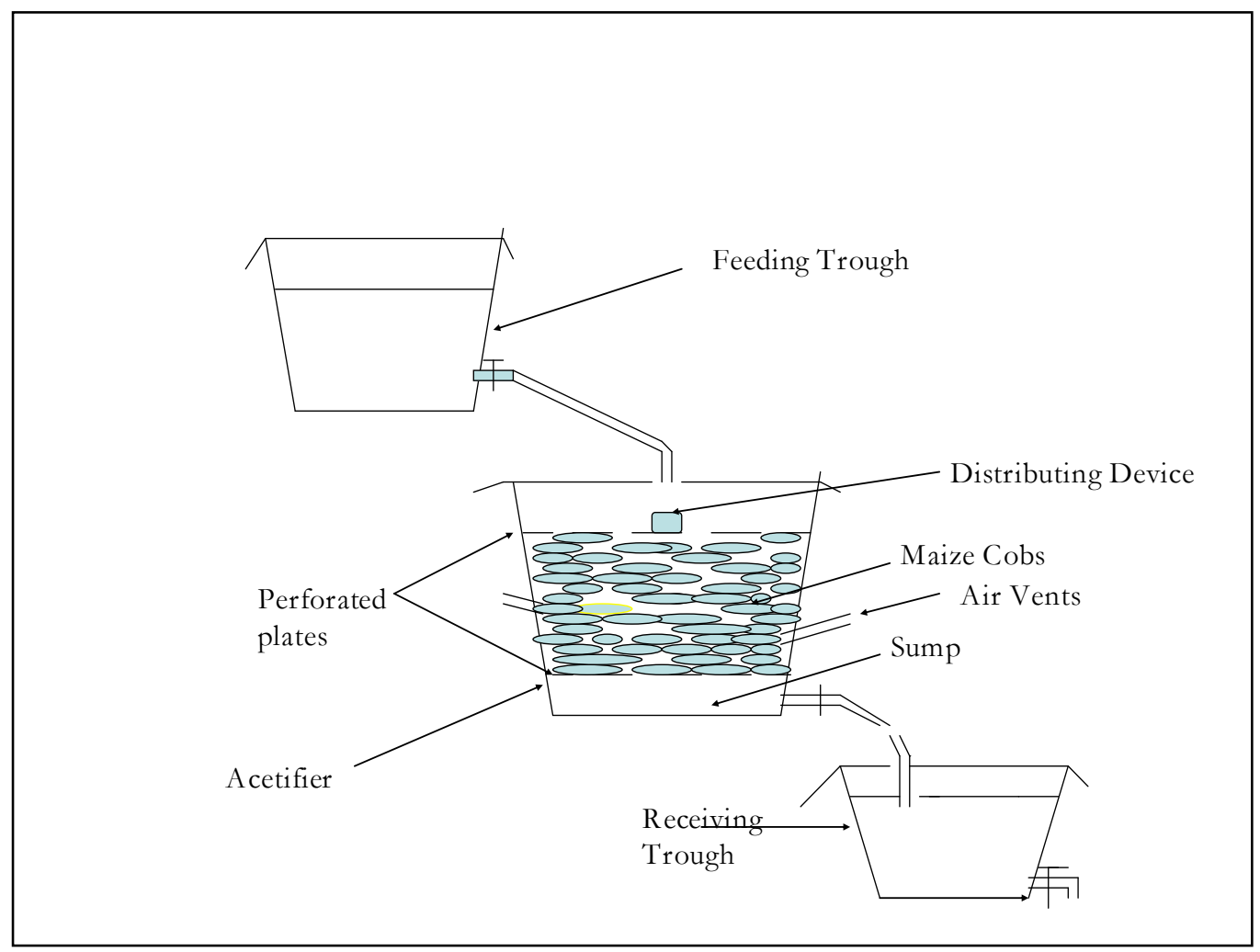

middle compartment of acetifier filled up with maize cobs soaked with mother vinegar. Maize cobs had been previously cleaned, sterilized and dried were soaked in mother vinegar for about six hours and packed fairy loosely in the central compartment of the acetifier between two perforated shelves. The bigger cobs were packed at the bottom and the smaller cobs near the top. This also consists of 6 ports for the admission of air in order to ensure the free air circulation through packing material, perforated PVC tubes were fitted horizontally. (Length equals to half of diameter). A solid wooden block was placed at the upper part of the acetifier with direct facing to the feed in order to ensure an uniform distribution of feeding materials. The lower compartment served as a sump for the collection of vinegar. A plastic tap was fitted 6" from the bottom to facilitate the drainage of vinegar from the acetifier. Receiving trough was used to collect vinegar that was run off from the acetifier.

In the operation process, generator was run first with blend of $25 \%$ of alcoholic solution and
$75 \%$ of the starter (raw vinegar) that has gone through the generator for seeding. The subsequent batch was a mixture of $50 \%$ alcoholic stock and the first batch then $75 \%$ alcoholic solution and 25\% starter. (This fresh vinegar was re-circulated three or four times through the generator). Thereafter, fresh alcoholic solutions were fed to the generator and recirculation was done manually until reached the required acetic acid level. Feed rate was maintained at $30 \mathrm{ml} / \mathrm{min}$ at each run.

\section{Sensory Evaluation:}

A sensory evaluation was done to compare vinegar from generator with commercial toddy vinegar and artificial vinegar using 50 consumer panelists. Samples were coded with three digit random numbers and served in random order for the panelists. Panelists were asked to rank each quality parameter of vinegar using 5- point Hedonic scale as 5 for like very much and 1 for dislike very much. 


\section{Statistical Analysis:}

The data were analyzed and obtained mean and standard deviation. Mean comparison was done using ANOVA and Independent sample ttest using SPSS 10 statistical package. Data obtained from sensory evaluation were analyzed by MINITAB Statistical package using Friedman test.

\section{Results and Discussion}

Changes in the alcohol levels during the fermentation period are given in figure 2. After inoculating with Bakers Yeast, alcohol level was rapidly raised during the alcoholic fermenting period up to a peak. Twelve percent TSS coconut water reached to a $5.5 \%$ alcohol level whereas $20 \%$ TSS level maximum of $11.35 \%$ alcohol level at the $8^{\text {th }}$ day of alcoholic fermentation. During acetic fermentation alcohol level drastically reduced to very low level. Sri Lanka Standard Institute (SLSI) specified that (SLS 168: 1999) the residual ethyl alcohol \% in the vinegar sample should not be more than $1 \%$ by volume, maximum.

The average TSS content of mature coconut is about $4.0 \%$. According to the fig 2 , alcohol level increases at different levels with respect to the sugar level. During yeast fermentation, sugar converts into alcohol (Gunathilake K.D.P.P. et.al) consumption of sugar by yeasts. After inoculating with mother vinegar, brix value changed slightly and eventually gains a constant value. The $\mathrm{pH}$ value of matured coconut water was 5.48. During the alcoholization period there is a declining trend in $\mathrm{pH}$ level. Acetobactor is unusually acid tolerant, growing well below $\mathrm{pH}$ 5.0. (http://en.wikipidia.org/wiki/acetic acid bacteria) Therefore during the acetification period a preferable media was formed for those kinds of bacteria, while others can't grow. During alcoholization period, titratable acidity rose up to peak of $0.3-0.5 \%$ from zero acidity. According to the Fig 3, after inoculating with mother vinegar there was an increasing trend in acetic acid level. Treatment 1 (12\% TSS) unable to obtain $4 \%$ acetic acid level. Sample 3 with 17\% TSS, obtained a peak of $6 \%$ acetic level within 37 days.
That is the maximum acetic acid level observed within the studies period. According to SLSI specification for coconut water vinegar (SLS 168:1999), the total acidity as acetic shall not be less than $4 \%(\mathrm{~m} / \mathrm{v})$ and not more than $13.0 \%$ $(\mathrm{m} / \mathrm{v})$.

Treatment $3,17^{0}$ brix was selected for applying the vinegar generator, because it gain maximum titratable acidity within relatively low time period.

Table 1. Average changes of acetic acid level during the Generator Process at the 6 hours cycle

\begin{tabular}{|l|c|}
\hline Cycles & Acetic acid level \% \\
\hline 1 & 1.08 \\
2 & 1.32 \\
3 & 2.70 \\
4 & 3.54 \\
5 & 4.32 \\
6 & 4.98 \\
7 & 4.86 \\
8 & 5.43 \\
9 & 5.30 \\
10 & 5.20 \\
11 & 5.23 \\
12 & 5.18 \\
\hline
\end{tabular}

The vinegar generator was designed to provide the maximum surface exposure for volume of vinegar stock in order to supply enough air for the acetic acid bacteria efficiently and quickly oxidize the alcohol to acetic acid. According to the results obtained, coconut water vinegar gained $4 \%-4.8 \%$ of acetic acid level at 5 th cycle. The maximum time period taken for the process was about 32 hours or 2 working days and by controlling the feeding of substrate into acetifier so that it matches the oxidation rate and almost complete conversion to acid was achieved whereas normal vinegar makingprocedure take 37 days to obtain a maximum vinegar strength, SLSI specified (SLS 168:1999), total acidity as acetic acid of coconut water vinegar shall in between $4 \%-13 \%$ $(\mathrm{m} / \mathrm{v})$. 
Figure 2. Changes in alcohol \% during fermentation 1

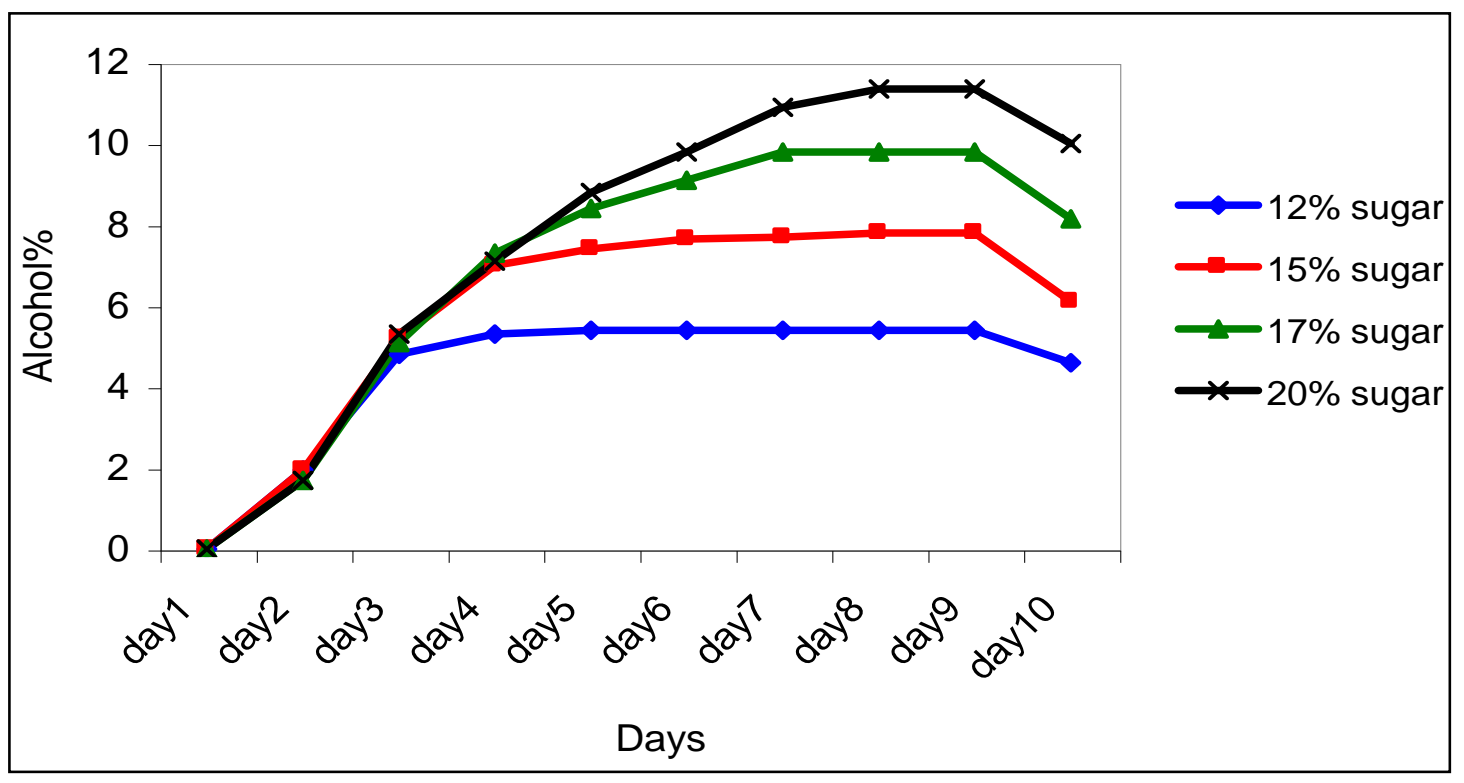

Figure 3. Changes in Titratable Acidity

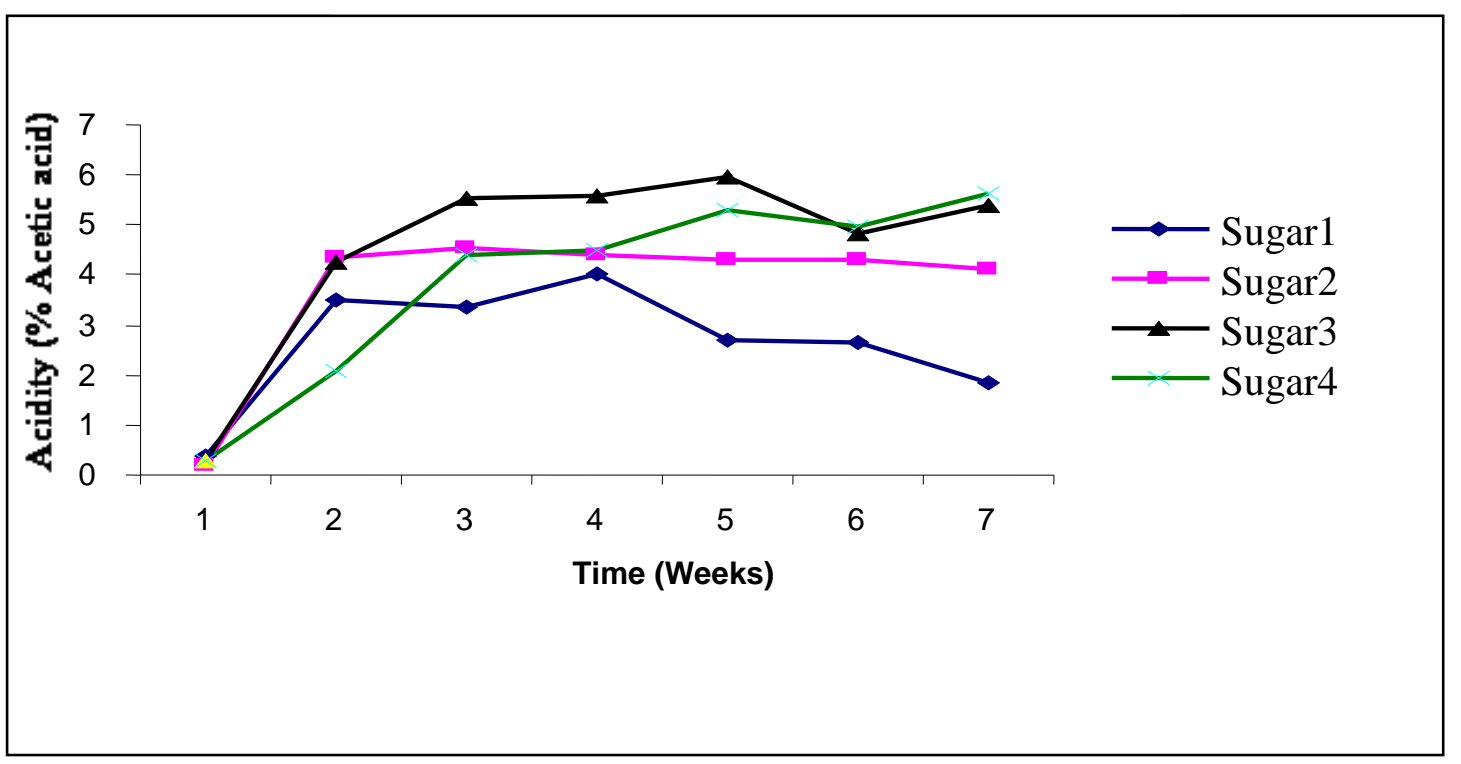


Table 2. Results of sensory evaluation of pickles prepared with different types of vinegar

\begin{tabular}{|l|c|c|c|c|}
\hline \multicolumn{1}{|c|}{ Samples } & Taste & colour & Aroma & $\begin{array}{c}\text { Overall } \\
\text { acceptability }\end{array}$ \\
\hline 1. Coconut water vinegar & $4.1 \mathrm{a}$ & $4.0 \mathrm{a}$ & $3.6 \mathrm{a}$ & $4.0 \mathrm{a}$ \\
2. Coconut toddy vinegar & $4.0 \mathrm{a}$ & $4.0 \mathrm{a}$ & $3.5 \mathrm{a}$ & $3.9 \mathrm{a}$ \\
3. Artificial vinegar & $3.4 \mathrm{~b}$ & $3.5 \mathrm{~b}$ & $2.5 \mathrm{~b}$ & $3.0 \mathrm{~b}$ \\
\hline
\end{tabular}

[Note: values in a column followed by same letter are not statistically significant (at 5\%)]

\section{Sensory Evaluation:}

According to the results of sensory evaluation for the taste, colour, aroma and overall acceptability showed that the coconut water vinegar and coconut toddy vinegar were highly acceptable compared with commercial artificial vinegar and suggesting coconut water vinegar can be used as a good alternative for scarce coconut toddy vinegar.

\section{Conclusion}

This study revealed that coconut water adjusted to $17^{0}$ TSS and allowing for 5 days alcoholic fermentation period and then for acetic fermentation at the "vinegar generator" could yield a most acceptable vinegar within 3 cycles or runs, otherwise it takes about 37 days to convert coconut water to vinegar. So, Vinegar Generator can be successfully applied for accelerate the production procedure of coconut water vinegar.

\section{Acknowledgement}

The authors are deeply grateful to the CESS FUND for the financial support and the staff of Coconut Processing Research Division of the institute for various supports.

\section{References}

Anon, 2004a, Central Bank of Sri Lanka, D.C.pp 35-36

Anon, 2004b annual report, Coconut Research Board, pp1-4
AOAC International, 1995, Official Methods of Analysis, $16^{\text {th }}$ Edition, $5^{\text {th }}$ Revision, Assoc. Official Analytical Chemists, Gaithersburg, MD 987.08

Bureau of Ceylon Standards, Specification for artificial vinegar, SLS 625:1983.

Coconut Research Institute, 1971, Coconut toddy vinegar by the Generator Process, leaflets no. 22

Fernandez ,W.L., (1988).Coconut water vinegar making in the Philippines, coconut today, pp92-106

Gunathilake K.D.P.P. (2005). ”Manufacturing of coconut water vinegar and some observation on the physico-chemical and sensory quality of the product" in proceedings of the $61^{\text {st }}$ Annual Session of Sri Lanka Association for the Advancement of Science

Samarajeewa, U. and M.P. Thisera, 1975, Use of Ebulliometer for alcohol determination in coconut toddy, Ceylon Coconut Quarterly, Coconut Research Institute

Sri Lanka Standards Institution, specification for coconut vinegar, $2^{\text {nd }}$ revision, SLS 168:1999. 